\title{
BURNOUT AMONG ANAESTHESIOLOGISTS IN INDIA. A QUESTIONNAIRE BASED STUDY
}

\author{
ANNIE SHEEBA JOHN ${ }^{1 *}$, SENTHIL KUMAR T ${ }^{2}$ \\ ${ }^{1}$ Department of Anaesthesiology, Mahatma Gandhi Medical College and Research Institute, Sri Balaji Vidyapeeth, Pondichery, Tamil Nadu, \\ India. ${ }^{2}$ Medical Intensive Care Unit, Meenakshi Medical Hospital, Thanjavur, Tamil Nadu, India. Email: dr.anniej@yahoo.com
}

Received: 26 March 2021, Revised and Accepted: 14 May 2021

ABSTRACT

Objectives: Small acute stress events occurring every day at work, can gradually lead to long-term, chronic stress. Burnout syndrome is the response to chronic occupational stress experienced by the person. We aimed to assess the prevalence of burnout among practicing anaesthesiologists in India and its association with personal and professional characteristics.

Methods: A cross-sectional survey study was conducted, wherein a questionnaire was emailed to 5000 anaesthesiologists. An anonymous selfadministered questionnaire consisting of socio-demographic, career, and work conditions, and Maslach Burnout Inventory-Human Services Survey (MBI-HSS) was used. Data were analysed according to the guidelines for data processing with SPSS and an analysis of the scales used.

Results: There were 1238 responders, with a response rate of $24.7 \%$. A total of 864 completed responses were considered for analysis. The prevalence of emotional exhaustion, depersonalisation, and low professional outcome among our responders was 39.5\%, 65\%, and 50.6\%. Senior residents showed a high prevalence of burnout in all subsets compared to other designation ( $\mathrm{p}<0.001)$. Increased prevalence was seen in the $26-35$ years age group, those working around $12 \mathrm{~h} /$ day, doing 7-10 night shifts per month, and perceived poor remuneration.

Conclusion: We conclude, that chronic stress and burnout are prevalent among anaesthesiologists in India at alarming levels. Coping strategies and relaxation techniques are necessary to reduce burnout and increase work efficiency.

Keywords: Burnout, India, Anesthesiologist, Survey.

(C) 2021 The Authors. Published by Innovare Academic Sciences Pvt Ltd. This is an open access article under the CC BY license (http://creativecommons.org/ licenses/by/4.0/) DOI: http://dx.doi.org/10.22159/ajpcr.2021v14i7.41224. Journal homepage: https://innovareacademics.in/journals/index.php/ajpcr

"While anaesthesia, like all of medicine, is considered to be increasingly safe for patients, it is becoming more dangerous for its practitioners."

Jackson, 1999

\section{INTRODUCTION}

Anaesthesiology is considered one of the stressful fields in medical practice [1-3]. Anaesthesiologists work in multiple domains including peri-operative care, intensive care, pain management, emergency, and trauma. They are active researchers, teachers, and bear hospital administrative responsibilities.

Burnout syndrome is chronic occupational stress affecting both physical and cognitive function. It can cause work exhaustion, sleepiness, decreased interest in work, lack of enthusiasm, low self-esteem, and increase susceptibility to illness leading to decreased work efficiency $[4,5]$. Continuous work in a fast-paced environment can lead to mental and physical exhaustion [6]. Mental wellness is as important as physical wellbeing but is often neglected. Prolonged mental stress and burnout are an important occupational hazard for health professionals. Most studies on Indian medical practitioners, especially anesthesiologists, identified high levels of work stress and burnout $[3,7,8]$.

An ever-changing workplace environment, the need to stay updated with every new revolution in our field, the drive to remain competent, the medico-legal trepidations, and the urge for research and publication are all passively burning us each day. We aimed to assess the prevalence of Burnout among practicing anaesthesiologists in India and its association with personal and professional characteristics.

\section{METHODS}

Study design and sampling

An online survey was conducted over a period of two months during May-June 2015 after obtaining institutional ethical committee approval.
Delphi method was followed for questionnaire preparation. Initially, an in-depth literature search was done using various search enginesGoogle Scholar, PubMed, Proquest, and Delnet. Based on the literature gathered, questions were prepared related to the aim of this study. Next, the questions were analysed by the senior faculties in the department for relevance to the study (content validation). Following this, a pilot survey using the preliminary questionnaire (excluding Maslach Burnout Inventory-questionnaire) was conducted in our department and "testretest" done for comprehension and flaws (format validation). After the validation of the questionnaire in the department, a final questionnaire was prepared.

\section{Survey tool}

An anonymous self-administered questionnaire consisting of 44 questions, divided into three parts were prepared to collect data. Part 1 aimed to collect socio-demographic and family data, and Part 2 was related to career and work conditions. Part 3 was the Maslach Burnout Inventory-Human Services Survey (MBI-HSS) consisting of a set of 22 questions divided into three subsets. The subsets were Emotional Exhaustion (EE), Depersonalization (DP), and Low Professional Outcome (LPO). Each question was scored on a 7 point scale $(0-6)\{0=$ never, $1=$ few times a year, $2=$ once $a$ month, 3 = few times a month, 4 = once a week, 5 = few times a week, 6 = every day\}. The subsets were scored separately and the degree of burnout is expressed independently for each subset and not by the cumulative score of all subsets. For emotional exhaustion, a score $\leq$ of 17 is low, 18-29 as moderate, and $\geq 30$ as high. Similarly, for depersonalisation score of $\leq 5$ classified as low, 6-11 as moderate, and $\geq 12$ as high. Contrary to EE and DP, Low Professional outcome is inversely related to the score, that is, higher the score better the perceived professional outcome. LPO is high if the score was $\leq 33$, moderate with 34-39, and low if score $\geq 40$. A high score in the first two subsets and a low score in the last subset indicate a high level of burnout [9-11]. 
Data collection and analysis

Anesthesiologists registered with the Indian Society of Anesthesiologists were emailed a link to the questionnaire. Data were analysed using Microsoft ${ }^{\circledR}$ Excel (2013), IBM SPSS Statistics for Windows version 22, Armonk, NY: IBM Corp. Descriptive data expressed as percentages and numbers. Burnout score was calculated using MBI guidelines and a Chi-square test was used for categorical data. Data were considered significant if $\mathrm{p}<0.05$.

\section{RESULTS}

Out of the 5000 emails sent, 1238 responded. The response rate was $24.7 \%$. We excluded postgraduate students from the analysis as we aimed to concentrate on practicing anaesthesiologists and not pursuing residents. After excluding postgraduates, a total of 864 completed responses were analysed to assess the prevalence of Burnout. Data of those respondents with high and moderate burnout scores were included for correlation analysis. Our respondents were predominantly males $($ males $=69 \%$, females $=30.4 \%$, and transgender $=0.6 \%$ ); assistant professors $(22.3 \%)$ followed by senior residents $(21.4 \%)$ and within age group of $26-35$ years $(36.1 \%)$. Personal data showed that $92 \%$ of our respondents were married and had two children (41.2\%).

Table 1 shows the socio-demographic and professional data of the respondents. Table 2 shows the results of questions on job perception and coping strategy followed by the anaesthesiologists. The distribution of burnout subscales according to the socio-demographic and job characteristics of the respondent anaesthesiologists are summarized in Tables 3 and 4 . Based on the analysis, 39.6\% of the respondents had emotional exhaustion, $65 \%$ experienced depersonalisation, and $50.6 \%$ had low professional outcomes (Fig. 1). The majority of our responders (58.5\%) felt that their work is not recognized by society or hospital administration (Fig. 2).

The analysis showed that the prevalence of burnout was significantly high in senior residents $(\mathrm{p}<0.001)$, younger age group anaesthesiologist (26-35 years, $\mathrm{p}<0.05)$, more than $8 \mathrm{~h} /$ day of work, and more than 10 -night shifts per month. The three subsets of burnout are not mutually exclusive, so a person can have burnout in more than one subset or in all subsets, which indicates a high risk for burnout syndrome. Around

Table 1: Socio-demographic and job characteristics of respondent anesthesiologists $(\mathrm{N}=864)$

\begin{tabular}{|c|c|c|c|}
\hline Gender & $\%$ (n) & Designation & $\%(n)$ \\
\hline Female & $30.4(263)$ & $\begin{array}{l}\text { Junior Resident/post- } \\
\text { graduate }\end{array}$ & $11.1(108)$ \\
\hline Male & 69 (597) & Senior Resident & $21.4(208)$ \\
\hline Transgender & $0.6(5)$ & Assistant Professor & $22.3(217)$ \\
\hline Age in years & $\%$ (n) & Associate Professor & $12.2(119)$ \\
\hline $26-35$ years & $36.1(312)$ & Professor (138) & $14.2(138)$ \\
\hline $36-45$ years & $32.7(283)$ & $\begin{array}{l}\text { Consultant Anesthetist } \\
\text { (Pvt Hosp) }\end{array}$ & $18.7(182)$ \\
\hline 46-55 years & $17.1(148)$ & Annual income & \\
\hline $56-65$ years & 11.4 (99) & $<5$ lakhs/annum & $9.3(79)$ \\
\hline$>65$ years & $2.7(23)$ & 6-10 lakhs/annum & $32.6(277)$ \\
\hline Marital status & $\%$ (n) & 11-15 lakhs/annum & $30.7(261)$ \\
\hline Yes & $92.5(803)$ & 16-20 lakhs/annum & $12.6(107)$ \\
\hline No & $7.06(61)$ & >20 lakhs/annum & $14.8(126)$ \\
\hline Children & $\%(n)$ & $\begin{array}{l}\text { Average number of } \\
\text { hours of work/day }\end{array}$ & $\%(n)$ \\
\hline None & $23.6(204)$ & $<4$ h/day & $2.3(20)$ \\
\hline 1 child & $32.6(282)$ & 4-8 h/day & $30.4(263)$ \\
\hline 2 children & $41.2(356)$ & $8-12$ h/day & $57.5(497)$ \\
\hline$>2$ children & $2.5(22)$ & $>12$ h/day & $9.7(84)$ \\
\hline Vacations/year & $\%(n)$ & $\begin{array}{l}\text { Average number of } \\
\text { night shifts/ month }\end{array}$ & $\%$ (n) \\
\hline None & $16.2(140)$ & $<4$ shifts $/$ month & $45.3(391)$ \\
\hline 1 & $37.2(321)$ & 4-6 shifts/month & $33.6(290)$ \\
\hline 2 & $31.4(271)$ & 7-10 shifts/month & $15.6(135)$ \\
\hline$>2$ & $15(130)$ & $>10$ shifts/month & $5.6(48)$ \\
\hline
\end{tabular}

$5 \%(46)$ of the anesthesiologist had high burnout in all subsets while $16 \%(140)$ doctors showed moderate levels in the three subsets.

\section{DISCUSSION}

Herbert Freudenberger, an American psychologist, coined the term "Burnout" in 1974 [10]. Subsequently, in 1986, Christian Maslach categorized Burnout into three domains including Emotional exhaustion, Depersonalization, and Low professional outcome, and introduced a questionnaire-based tool called "Maslach Burnout Inventory" to identify the risk of Burnout syndrome among individual [11].

Despite a good professional environment and remuneration, studies done in western countries have also shown a high prevalence of burnout among doctors and more so among anaesthesiologists [12,13]. Studies conducted in India, similarly, have shown high-stress levels and burnout among different categories of health professionals. The majority of these studies used self-prepared questionnaires and targeted smaller samples. We aimed to assess the prevalence of burnout on a larger sample using an online platform and use a standardized questionnaire. Job and personal characteristics associated with burnout were also assessed, as the burden of burnout depends not only on work demand or workplace environment but also on personal and social impact [14]. Our study revealed that more than half of our respondents were experiencing burnout. Our findings were similar to a survey conducted by Bakshi et al. in 2017, which showed a high prevalence of work stress, significantly in males and associated with increased work hours and work on weekends [7]. Senior residents, in our study, had more prevalence of burnout compared to assistant professors and professors. $(\mathrm{p}<0.05)$. Steve et al. studied burnout on perioperative physicians and concluded that busy, young doctors are at risk for Burnout [15].

The higher the designation, the lower was the prevalence of burnout. $(p<0.05)$ Academic physicians grow up in the hierarchy to achieve higher positions, they learn to manage stress and develop coping strategies more effectively [16]. Anesthesiologists working in corporate hospitals also showed scores similar to faculties in a teaching institution.

Studies have shown varying results relating gender with burnout. In our study, there was no statistical difference in the prevalence of

Table 2: Job perception and coping strategy among respondent anesthesiologists

\begin{tabular}{|c|c|c|c|}
\hline $\begin{array}{l}\text { How would } \\
\text { I grade my } \\
\text { remuneration? }\end{array}$ & $\%(n)$ & $\begin{array}{l}\text { Pressure for } \\
\text { publication and } \\
\text { presentation? }\end{array}$ & $\%(n)$ \\
\hline Poor & $26.6(230)$ & Yes, for promotion & 18. \\
\hline Satisfactory & $51(4$ & $\begin{array}{l}\text { Yes, for increment/ } \\
\text { incentives }\end{array}$ & \\
\hline Good & 20.5 (177) & $\begin{array}{l}\text { yes, for academic } \\
\text { reasons }\end{array}$ & 22.3 (193) \\
\hline Excellent & $1.9(16)$ & $\begin{array}{l}\text { No; I have the liberty to } \\
\text { work by my interests }\end{array}$ & $62(536)$ \\
\hline $\begin{array}{l}\text { How do I relax/ } \\
\text { de-stress? }\end{array}$ & $\%(n)$ & $\begin{array}{l}\text { Which factors at work, } \\
\text { if changed would } \\
\text { decrease my stress } \\
\text { level to large extent? }\end{array}$ & $\%(n)$ \\
\hline Musi & & Increase in remuneration & 9) \\
\hline Movies & 39.7 & $\begin{array}{l}\text { Decrease the number of } \\
\text { night duties/per month }\end{array}$ & $22.4(190)$ \\
\hline Yoga & $11.3(98)$ & $\begin{array}{l}\text { Better anesthesia } \\
\text { equipment at work }\end{array}$ & $27.1(230)$ \\
\hline Sports activities & 10.1 (87) & $\begin{array}{l}\text { Decrease in family } \\
\text { related issues }\end{array}$ & $11.1(94)$ \\
\hline $\begin{array}{l}\text { Physical } \\
\text { exercise }\end{array}$ & $31.9(276)$ & $\begin{array}{l}\text { Better surgeon- } \\
\text { anesthetist rapport }\end{array}$ & $31.1(264)$ \\
\hline Reading & $31.1(272)$ & All the above & $40.8(346)$ \\
\hline
\end{tabular}


Table 3: Distribution of burnout subscales according to the socio-demographic characteristics of the respondent anesthesiologists

\begin{tabular}{|c|c|c|c|}
\hline $\begin{array}{l}\text { Data } \\
\mathrm{n}=\text { Total } \\
\text { respondents in } \\
\text { each category }\end{array}$ & $\begin{array}{l}\text { Emotional } \\
\text { exhaustion } \\
(n=342) \\
\% \text { (n) }\end{array}$ & $\begin{array}{l}\text { Depersonalisation } \\
(n=567) \\
\%(n)\end{array}$ & $\begin{array}{l}\text { Low } \\
\text { professional } \\
\text { outcome } \\
(n=438) \\
\%(n)\end{array}$ \\
\hline \multicolumn{4}{|l|}{ Gender } \\
\hline Male (596) & $68(240)$ & $67.7(384)$ & 68 (298) \\
\hline Female (263) & $28(99)$ & 31.7 (180) & 31.3 (137) \\
\hline Transgender (5) & $1(3)$ & $0.5(3)$ & $0.7(3)$ \\
\hline $\mathrm{p}$ value & 0.428 & 0.703 & 0.000 \\
\hline \multicolumn{4}{|l|}{ Age (Years) } \\
\hline $26-35(312)$ & 44.7 (153) & $41.6(236)$ & $40.1(176)$ \\
\hline $36-45(282)$ & 34.2 (117) & $33.6(191)$ & 36.7 (161) \\
\hline $46-55$ (148) & $11(41)$ & $15.3(87)$ & $13.4(59)$ \\
\hline $56-65$ (99) & $7(27)$ & $8.4(48)$ & $7(33)$ \\
\hline$>65(23)$ & $0.1(4)$ & $0.9(5)$ & $1.8(8)$ \\
\hline $\mathrm{p}$ value & 0.000 & 0.071 & 0.577 \\
\hline \multicolumn{4}{|l|}{ Family } \\
\hline Nuclear (608) & $70(240)$ & $69(394)$ & $70.5(309)$ \\
\hline Joint (256) & $29.8(102)$ & $30.5(173)$ & $29.5(129)$ \\
\hline $\mathrm{p}$ value & 0.935 & 0.072 & 0.578 \\
\hline \multicolumn{4}{|l|}{ Vacation/Year } \\
\hline None (140) & $23.3(80)$ & $16(95)$ & $18(80)$ \\
\hline 1/yr (321) & $36.2(124)$ & 39.1 (222) & 40 (178) \\
\hline $2 /$ yr (271) & $29.5(101)$ & $30.6(174)$ & $28(123)$ \\
\hline$>2 / \operatorname{yr}(130)$ & $11(37)$ & $11.6(76)$ & $12.7(56)$ \\
\hline $\mathrm{p}$ value & 0.000 & 0.064 & 0.013 \\
\hline
\end{tabular}

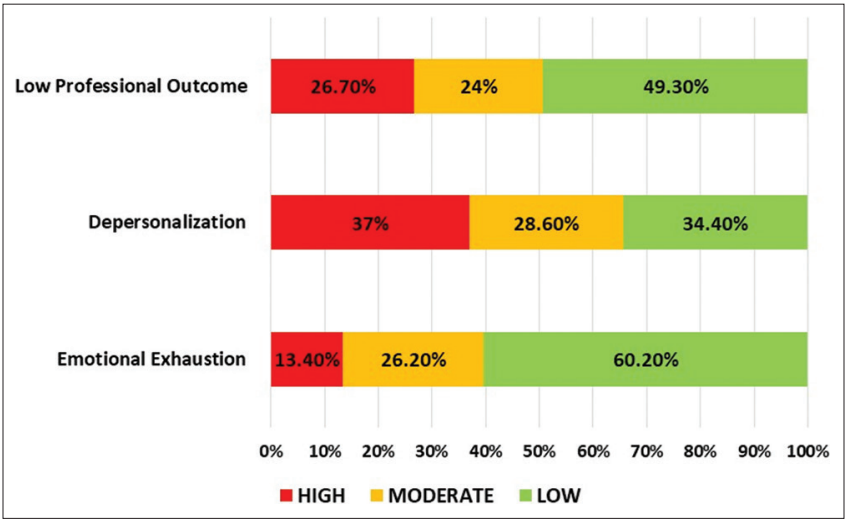

Fig. 1: Prevalence of burnout subsets among respondent anesthesiologists
Burnout among different genders. A study by Linzer et al. showed that female physicians had more work stress compared to males in the USA. ( $28 \%$ vs. $21 \%, \mathrm{p}<0.05)$, whereas the difference in Dutch physicians was not significant [17]. It is apparent from previous studies and our study that there is still no consensus regarding gender playing a role in the occurrence of burnout among doctors.

Finnish anesthetists studied the occurrence of stress in on-call consultants and positively proved that being frequently on-call correlated with severe stress symptoms and burnout. The symptoms increased with the increasing on-call workload and decreased during vacations, they also found that younger anesthetists had more symptoms compared to their older colleagues [18]. Burnout and night duties were positively correlated, the higher the number of duties, the higher the risk of burnout. Burnout was high in doctors doing 7-10 night shifts. (EE and DP p<0.001, LPO p <0.05)

Long working hours and sleep deprivation cause fatigue and mental exhaustion, which can reduce attention span and memory. Surgeons with high levels of burnout reportedly committed more medical errors compared to others. Each point increase in depersonalization was associated with an $11 \%$ increase in the likelihood of reporting an error and a $5 \%$ raise of error with each point increase in emotional exhaustion [19]. Gravenstein et al. found that anesthesiologists who often worked beyond their limitations lead to more errors [20]. Our survey showed that more than $50 \%$ of our respondents who work beyond $8 \mathrm{~h}$ /day had emotional exhaustion and depersonalisation $(p<0.001)$ but their professional outcome was not affected. $(p=0.551)$.

Good remuneration is very important for job satisfaction and improved quality of life. The impact of remuneration on job satisfaction mainly depends on the employee's perception of the given remuneration [21]. This is confirmed by our findings that were $26.6 \%$ of our respondents felt that remuneration offered for their designation or qualification was poor. Doctors with a perception that their remuneration is good had a low prevalence of Burnout in comparison to those who were not satisfied with the remuneration. $(\mathrm{p}<0.001)$

The debate on whether research is mandatory for clinicians with regard to promotion is a never-ending argument. Studies suggest that the quality of teaching improves if the faculty is involved in research activities and has an extra edge during promotions, compared to their counterparts [22]. On the contrary, few authors identified that if research is essential for promotion then it may pressurize the teachers and increase stress [23]. In our study, the majority of our respondents $(62 \%)$ expressed that they have the liberty to conduct research based on their interests whereas $25 \%$ accepted that there is pressure for publication to gain promotion or increment.

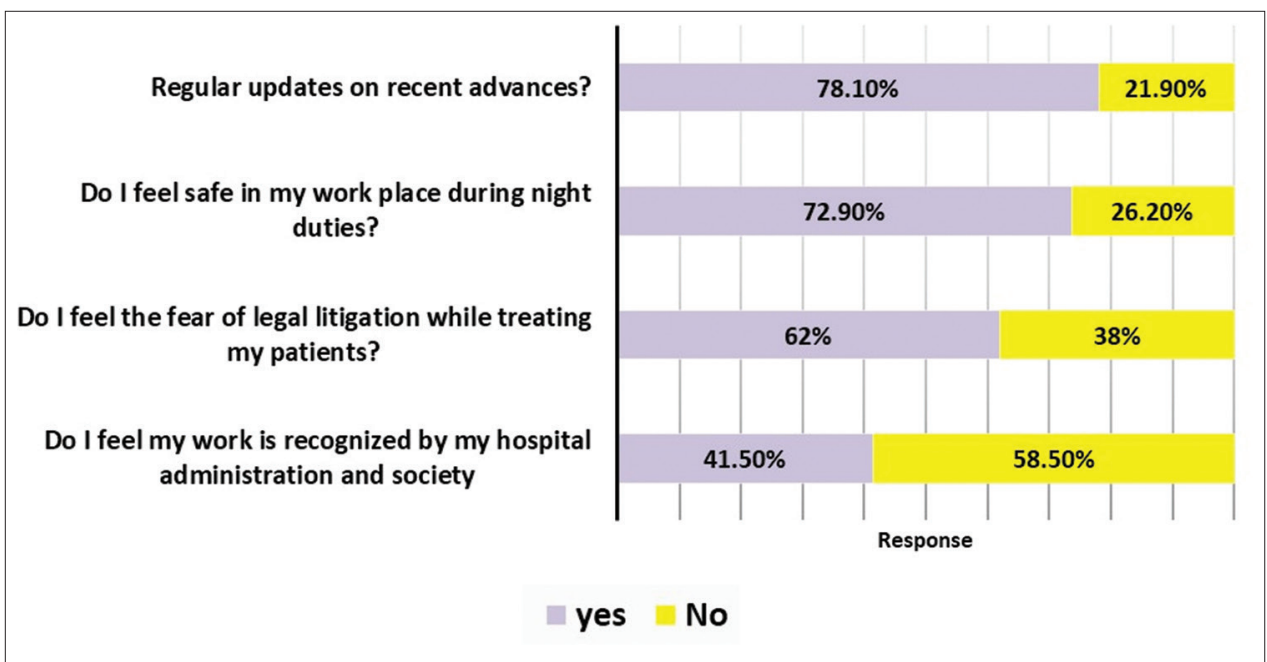

Fig. 2: Work perception 
Table 4: Distribution of burnout subscales according to job characteristics of the respondent anesthesiologists

\begin{tabular}{|c|c|c|c|}
\hline $\begin{array}{l}\text { Data } \\
\mathrm{N}=\text { Total respondents in each } \\
\text { category }\end{array}$ & $\begin{array}{l}\text { Emotional Exhaustion } \\
(\mathrm{n}=342) \\
\%(\mathrm{n})\end{array}$ & $\begin{array}{l}\text { Depersonalization }(n=567) \\
\%(n)\end{array}$ & $\begin{array}{l}\text { Low professional outcome } \\
(\mathrm{n}=438) \\
\%(\mathrm{n})\end{array}$ \\
\hline \multicolumn{4}{|l|}{ Designation (N) } \\
\hline Senior Resident (208) & $31(106)$ & $28.3(161)$ & $29.4(129)$ \\
\hline Assistant professor (217) & $28.3(97)$ & $27.1(154)$ & $30.1(132)$ \\
\hline Associate Professor (119) & $11.4(39)$ & $11.2(64)$ & $11.1(49)$ \\
\hline Professor (138) & $10(34)$ & $12.1(69)$ & $12.3(54)$ \\
\hline Consultant Anesthesiologist (182) & $19.2(66)$ & 20.9 (119) & $16.8(74)$ \\
\hline$p$ value & 0.000 & 0.000 & 0.000 \\
\hline \multicolumn{4}{|l|}{ Night shift/month } \\
\hline$<4$ shifts/month (391) & $33.6(115)$ & $38.6(219)$ & $40.6(178)$ \\
\hline $4-6 /$ month $(290)$ & $39.1(134)$ & $36.5(207)$ & $37.2(163)$ \\
\hline 7-10/month (135) & $17.2(59)$ & $18.1(103)$ & $15.5(68)$ \\
\hline$>10$ /month (48) & $10(34)$ & $6.7(38)$ & $7.3(32)$ \\
\hline $\mathrm{p}$ value & 0.000 & 0.000 & 0.0462 \\
\hline \multicolumn{4}{|l|}{ Work hours/day } \\
\hline$<4$ h/day $(20)$ & $1.1(4)$ & $5(6)$ & $2.2(10)$ \\
\hline $4-8 \mathrm{~h} /$ day (263) & $22(75)$ & $27.1(154)$ & $29.2(128)$ \\
\hline $8-12$ h/day (497) & $60(207)$ & $60.1(341)$ & $57(250)$ \\
\hline$>12 \mathrm{~h}(84)$ & $15.7(54)$ & $11.6(66)$ & $11.4(50)$ \\
\hline $\mathrm{p}$ value & 0.000 & 0.000 & 0.551 \\
\hline \multicolumn{4}{|l|}{ Remuneration } \\
\hline Excellent (16) & $0.05(2)$ & $0.5(3)$ & $0.2(1)$ \\
\hline Good (177) & $12.8(44)$ & $17.1(97)$ & $15(66)$ \\
\hline Satisfactory (441) & $54.3(186)$ & $51.1(290)$ & $52.5(230)$ \\
\hline Poor $(230)$ & $32.4(111)$ & $31.2(177)$ & $32.1(141)$ \\
\hline $\mathrm{p}$ value & 0.000 & 0.000 & 0.000 \\
\hline
\end{tabular}

A survey conducted to assess the psychological impact caused by medico-legal issues on Australian doctors showed that 59\% of their respondents had a medico-legal matter at some point in their career while $13 \%$ were having current issues. It highlighted that doctors with current medico-legal matters reported increased levels of disability (in work, social, or familial) and psychological morbidity [24]. To the best of our knowledge, no such survey has been done in our country to identify the impact of medico-legal issues on the well-being of doctors or the steps taken by the individual to prevent and handle such situations. In our survey, $62 \%$ of respondents felt that they have fear of medico-legal issues and concerns while treating patients. Studies have shown a wide gap in medico-legal knowledge and practice among both practicing doctors as well as pursuing postgraduates $[25,26]$. Regular updates and continuing professional development programs on medico-legal issues and their consequences are a need of the hour for health care professionals.

Recreation or relaxation techniques help to combat and reduce work stress. Various studies have proven that yoga and meditation reduce pain, relieve stress, increase energy, and attention span $[6,27,28]$. Music therapy is also an effective way to relax and de-stress. Music is the most preferred way to de-stress in our respondents (45\%) while 39\% of them prefer movies. A pre-post observational study was conducted by Goodman et al. based on mindfulness-based stress reduction on healthcare professionals. Training in mindfulness practices, including the body scan, mindful movement, meditation, and application of mindfulness at work was taught and concluded that significant reduction in burnout level and improve mental well-being was noted [29]. We also identified that doctors taking more than two vacations per year have experienced less burnout (emotional exhaustion) compared to those who do not take vacations at all.

There are several limitations to our study. First, the questionnaire was distributed by e-mail, and this can lead to responder bias, but such a mode of data collection was the feasible method to enroll a large number of participants into the study. Second, a pre-formed questionnaire may not have completely elicited the feelings of the responded anaesthesiologists. Third, causal associations are difficult to identify due to the cross-sectional design of this study.

\section{CONCLUSION}

We conclude that chronic stress and burnout are prevalent among Indian Anaesthesiologists at alarming levels. A combined effort needs to be undertaken by the individual and the institution to implement coping strategies to mitigate work-related burnout for a stress-free professional life to experience work efficiency at its best level.

\section{ACKNOWLEDGMENT}

The authors would like to thank the faculty of the Department of Anaesthesiology, MGMCRI, who helped in validating the questionnaire. We thank Prof. Dr. M Ravishankar for his constant guidance throughout the conduct of the study.

\section{AUTHORS' CONTRIBUTIONS}

Dr. Annie Sheeba J was involved in the planning of the study, preparation of the questionnaire, and writing, reviewing, and editing of the manuscript. Dr. Senthil Kumar collected and analyzed the data.

\section{CONFLICTS OF INTEREST}

The authors affirm no conflicts of interest, finance, or otherwise.

\section{AUTHORS' FUNDING}

No external funds were received for this research.

\section{REFERENCES}

1. Jackson S. The role of stress in anesthetist' health and well-being. Acta Anaesthesiol Scand 1999;43:583-602.

2. Kain ZN, Chan KM, Katz JD, Nigam A, Fleisher L, Dolev J, et al. Anesthesiologists and acute perioperative stress: A cohort study. Anesth Analg 2002;95:177-83.

3. Koshy RC, Ramesh B, Khan S, Sivaramakrishnan A. Job satisfaction 
and stress levels among anaesthesiologists of south India. Indian $\mathrm{J}$ Anaesth 2011;55:513-7.

4. Ruotsalainen JH, Verbeek JH, Mariné A, Serra C. Preventing occupational stress in healthcare workers. Cochrane Database Syst Rev 2015;4:CD002892.

5. Sandström A, Rhodin IN, Lundberg M, Olsson T, Nyberg L. Impaired cognitive performance in patients with chronic burnout syndrome. Biol Psychol 2005;69:271-9.

6. Gura ST. Yoga for stress reduction and injury prevention at work. Work Read Mass 2002;19:3-7.

7. Bakshi SG, Divatia JV, Kannan S, Myatra SN. Work-related stress: A survey of Indian anesthesiologists. J Anaesthesiol Clin Pharmacol 2017;33:86-91.

8. Grover S, Sahoo S, Bhalla A, Avasthi A. Psychological problems and burnout among medical professionals of a tertiary care hospital of North India: A cross-sectional study. Indian J Psychiatry 2018;60:175-88.

9. Mikalauskas A, Širvinskas E, Marchertienė I, Macas A, Samalavičius R, Kinduris $\breve{\mathrm{S}}$, et al. Burnout among lithuanian cardiac surgeons and cardiac anesthesiologists. Med Kaunas Lith 2012;48:478-84.

10. Freudenberger HJ. Staff burn-out. J Soc Issues 1974;30:159-65.

11. Maslach C, Jackson SE. Maslach Burnout Inventory Manual. $2^{\text {nd }}$ ed. Palo Alto, CA: Consulting Psychologists Press; 1986.

12. Nyssen AS, Hansez I. Stress, and burnout in anaesthesia. Curr Opin Anaesthesiol 2008;21:406-11.

13. De Oliveira GS, Ahmad S, Stock MC, Harter RL, Almeida MD, Fitzgerald PC, et al. High incidence of burnout in academic chairpersons of anesthesiology: Should we be taking better care of our leaders? Anesthesiology 2011;114:181-93.

14. Tyssen R, Vaglum P. Mental health problems among young doctors: An updated review of prospective studies. Harv Rev Psychiatry 2002;10:154-65.

15. Hyman SA, Michaels DR, Berry JM, Schildcrout JS, Mercaldo ND, Weinger MB. Risk of burnout in perioperative clinicians: A survey study and literature review. Anesthesiology 2011;114:194-204.

16. Shams T, El-Masry R. Job stress and burnout among academic career anaesthesiologists at an Egyptian university hospital. Sultan Qaboos Univ Med J 2013;13:287-95.

17. Linzer M, McMurray JE, Visser MR, Oort FJ, Smets E, de Haes HC.
Sex differences in physician burnout in the United States and the Netherlands. J Am Med Womens Assoc 2002;57:191-3.

18. Lindfors PM, Nurmi KE, Meretoja OA, Luukkonen RA, Viljanen AM, Leino TJ, et al. On-call stress among Finnish anaesthetists. Anaesthesia 2006;61:856-66

19. Shanafelt TD, Balch CM, Bechamps G, Russell T, Dyrbye L, Satele D, et al. Burnout and medical errors among American surgeons. Ann Surg 2010;251:995-1000.

20. Gravenstein JS, Cooper JB, Orkin FK. Work and rest cycles in anesthesia practice. Anesthesiology 1990;72:737-42.

21. Litwin J, Waśniewski J. The relation between remuneration and job satisfaction: A case study of public administration employees in pomerania region in Poland. Soc Lab Relat Theory Pract 2015;1:123-33.

22. Singh T. Research methodology simplified: Every clinician a researcher. Indian J Pharmacol 2011;43:224.

23. Sukhlecha A. Research publications: Should they be mandatory for promotions of medical teachers? J Pharmacol 2011;2:221-4.

24. Nash L, Daly M, Johnson M, Walter G, Walton M, Willcock S, et al. Psychological morbidity in Australian doctors who have and have not experienced a medico-legal matter: A cross-sectional survey. Aust N Z J Psychiatry 2007;41:917-25.

25. Singh R, Lahoti H, Gopal S, Patil S, Chandavarkar A. Knowledge, practices, and attitude of healthcare professionals towards medico-legal aspects in clinical practice: Results of a questionnaire-based survey. MedPulse Int J Gynaecol 2019;11:45-50.

26. Jambure M, Jambure A. A study on awareness and knowledge about medico-legal issues among interns and post graduate students. Int $\mathrm{J}$ Curr Med Appl Sci 2017;17:9-12.

27. Van der Klink JJ, Blonk RW, Schene AH, van Dijk FJ. The benefits of interventions for work-related stress. Am J Public Health 2001;91:270-6.

28. Michalsen A, Grossman P, Acil A, Langhorst J, Lüdtke R, Esch T, et al. Rapid stress reduction and anxiolysis among distressed women as a consequence of a three-month intensive yoga program. Med Sci Monit 2005;11:CR555-61.

29. Goodman MJ, Schorling JB. A mindfulness course decreases burnout and improves well-being among healthcare providers. Int J Psychiatry Med 2012;43:119-28. 